\title{
A simplified energy consumption model for fiber-based Next Generation Access Networks
}

\author{
Rafael Coomonte*, Carmen Lastres, Claudio Feijóo, Ángel Martín \\ CeDInt-Universidad Politécnica de Madrid, Campus de Montegancedo, Pozuelo de Alarcón, 28223 Madrid, Spain
}

\section{A R T I C L E I N F O}

Keywords:

Next GenerationAcces Networks

FTTH

Access Networks

Energy consumption

NGAN architectures

Fiber networks

\begin{abstract}
A B S T R A C T
ICTs account nowadays for $2 \%$ of total carbon emissions. However, in a time when strict measures to reduce energy consumption in all the industrial and services sectors are required, the ICT sector faces an increase in services and bandwidth demand. The deployment of Next Generation Networks (NGN) will be the answer to this new demand and specifically, the Next Generation Access Networks (NGANs) will provide higher bandwidth access to users. Several policy and cost analysis are being carried out to understand the risks and opportunities of new deployments, though the question of which is the role of energy consumption in NGANs seems off the table. Thus, this paper proposes a model to analyze the energy consumption of the main fiber-based NGAN architectures, i.e. Fiber To The House (FTTH) in both Passive Optical Network (PON) and Point-to-Point (PtP) variations, and FTTx/VDSL. The aim of this analysis is to provide deeper insight on the impact of new deployments on the energy consumption of the ICT sector and the effects of energy consumption on the life-cycle cost of NGANs. The paper presents also an energy consumption comparison of the presented architectures, particularized in the specific geographic and demographic distribution of users of Spain, but easily extendable to other countries.
\end{abstract}

\section{Introduction}

Reducing energy consumption is a main goal in many countries. As an example, European Union (EU) member states have agreed to reduce greenhouse gas (GHG) emissions by $20 \%$ in 2020 compared with 1990 levels (EC, 2008b). However, according to the SMART2020 report (GeSI, 2008), ICT (Information and Communication Technologies) sector emissions are expected to increase from 0.53 billion tonnes (Gt) carbon dioxide equivalent (CO2e) in 2002 to $1.43 \mathrm{GtCO} e$ in 2020. At the same time, several sources have reported that ICT-based opportunities, such as smart buildings, smart grids and smart transportation systems, can lead to emission reductions five times the size of the sector's own carbon footprint, i.e., up to 7.8 GtCO2e, or $15 \%$ of total emissions by 2020 (Labouze et al., 2008). Therefore, the positive effects of intensive use of ICTs (the stimulation of growth and jobs and the enabling of energy efficiency in other sectors of activity) are counterbalanced by its consumption of a growing proportion of the global energy budget (Teppayayon et al., 2009) and the so-called "rebound effects" (Bomhof et al., 2009).

Whatever the ultimate effects of ICTs are on energy consumption and GHG emissions, a significant degree of innovation is still required to increase the positive side of the above balance. Indeed, guided by the dynamics of the ICT markets and rather than a "green compromise" of society, we are witnessing the emergence of ubiquitous ultra-broadband networks, of cloud

\footnotetext{
* Corresponding author.

E-mail addresses: rcoomonte@cedint.upm.es (R. Coomonte), clastres@cedint.upm.es (C. Lastres), cfeijoo@cedint.upm.es (C. Feijóo), amartin@cedint. upm.es (Á. Martín).
} 
computing and of an explosion in new devices and sensors. These three innovations will be the main future building bricks of upcoming smart systems and the basis for a "dematerialisation" of the economy. In other words, each of these new developments exert an impact on the major blocks of energy consumption in ICTs: telecommunications networks, data centres and consumer equipment (Sutherland, 2009). Energy consumed in each of these areas is forecast to increase significantly by 2020 (GeSI, 2008), although the future share of consumption among them remains unclear (Sutherland, 2009).

Among the upcoming ICT developments mentioned above, Next Generation Access Networks (NGANs) are generally considered to be the most relevant because they will support renewed opportunities in the provision of ubiquitous broadband connectivity, applications and content. From their deployment, a wealth of innovations is highly expected. In line with these expectations, private players are slowly beginning to invest into the main deployments, whereas public administrations have jumped into encourage the development of these new infrastructures, supporting them through a range of recent initiatives (Gómez-Barroso and Feijóo, 2010).

Surprisingly, a discussion of energy consumption appears to be mostly absent from the main analysis of NGAN deployment. This absence occurs despite some early documents on the potential of energy consumption to make a significant contribution towards reducing the carbon footprint of the ICT sector (ITU, 2008) and despite the fact that conditions for the deployment of the access part of NGN are currently on the forefront of the debate about telecommunication markets and the level and modes of potential public involvement. For a discussion of these issues, see Gómez-Barroso and Feijóo (2009).

In this regard, the choice of which access technology to use has traditionally been a matter of deployment costs, re-use of the existing infrastructures and expectations of the needs of users. However, the contributions of NGANs to energy efficiency, their own impact on GHG and the risk of an increase in energy prices (IEA, 2010) all lead to the inclusion of energy consumption in the list of choice factors and to the introduction of the energy perspective in the policy debate on NGAN deployment. Citing Sutherland (2009), "forecasts for the energy consumption are complicated by the evolution [of telecommunications networks]... none of these processes is well understood or easily predicted". Thus, from the authors' perspective, this area remains one of high research interest and socio-economic relevance.

Therefore, the main objective of this research paper is to describe a simplified model for energy consumption of fibrebased NGANs that is able to provide comparisons across technologies. By deriving from these results, estimating both the impact of the energy consumption in the life-cycle cost of NGANs and the implications of new NGAN deployments on the ICT carbon footprint will be possible.

The paper is structured into 4 main sections in addition to this background. Section 2 reviews the methodology and assumptions for the energy consumption models presented later. Section 3 explains the main relevant aspects of network architectures for the different fibre-based NGAN technologies and also covers energy usage. In Section 4 , some results are introduced for each technology described. Derived from an analysis of the exposed results, some conclusions are presented in the closing section of this paper.

\section{Foundations of the model}

\subsection{Access technologies}

The model for energy consumption in NGANs departs from a review of all of the technologies suited for NGANs in the short and middle term. In general, broadband access technologies can be classified by the physical medium into two major groups: wired (or fixed line) technologies and wireless technologies.

Concerning the former access solutions, the main wired technologies are based on fibre, coaxial, copper wire and power line.

As for the classification of wireless technologies, two main sets of characteristics are considered: terrestrial versus satellite-based and fixed versus mobile wireless. Because of the requisites of NGANs, very high bandwidth for each user, only the terrestrial solutions can be considered to be adequate solutions. Wireless technologies are approximately 3-5 years behind fixed technologies in terms of data rates per user. However, they are not far from reaching the 10 $\mathrm{Mb} / \mathrm{s}$ level per user with some consistency. As a result, mobile broadband connections are predicted to overcome fixed wireless sometime in 2011-2013 (Nerandzic, 2008; Ouvrier, 2008; Aguado, 2009), and therefore, mobile broadband connections will be considered as a suitable (stand-alone or complementary) technological alternative to access technologies.

In the following discussion, only fixed fibre-based NGANs (PON and PtP variations of FTTH and FTTx/VDSL) and their energy requirements are taken into account, as they are considered to be the best technology choice for short-term NGAN deployments. This superiority is due mainly to the economic feasibility of their deployment over other access technologies (Analysys Mason, 2008, 2009; CMT, 2009; Feijóo and Gómez-Barroso, 2010). In addition the exponential increase of FTTH subscribers that is already occurring, and that will translate into a trend to use these access technologies instead of ADSL (Effenberger and El-Bawab, 2009).

\subsection{Energy assumptions}

Although the energy consumption of NGANs is mainly the result of network usage (approximately 60\%), there are other important phases along the NGAN life cycle that affects the total energy balance (Griffa et al., 2010). Examples of these 
Table 1

Summary of demographic data used in the analysis (Feijóo and Gómez-Barroso 2010).

\begin{tabular}{|c|c|c|c|c|c|c|c|c|c|c|c|}
\hline Zone & 1 & Il & III & IV & V & VI & VII & VIII & IX & $x$ & Total \\
\hline $\begin{array}{l}\text { Population density } \\
\quad\left(\text { inh } / \mathrm{km}^{2}\right)\end{array}$ & $>10 \mathrm{~K}$ & $10 \mathrm{~K}-5 \mathrm{~K}$ & $5 \mathrm{~K}-3 \mathrm{~K}$ & $3-1000$ & $1 \mathrm{~K}-500$ & $500-100$ & $100-50$ & $50-10$ & $10-5$ & $<5$ & \\
\hline $\begin{array}{l}\text { Number of } \\
\text { municipalities }\end{array}$ & 17 & 28 & 46 & 175 & 209 & 946 & 745 & 2.705 & 1.444 & 1.797 & 8.112 \\
\hline $\begin{array}{l}\text { Number of } \\
\text { households and } \\
\left.\text { businesses ( } n_{\text {user }}\right)\end{array}$ & 1.204 .353 & 2.613 .005 & 1.482 .028 & 3.219 .470 & 1.807 .866 & 3.987 .672 & 1.326 .987 & 1.817 .422 & 323.441 & 168.155 & 17.950 .398 \\
\hline $\begin{array}{l}\% \text { of households and } \\
\text { premises }\end{array}$ & $7 \%$ & $15 \%$ & $8 \%$ & $18 \%$ & $10 \%$ & $22 \%$ & $7 \%$ & $10 \%$ & $2 \%$ & $1 \%$ & \\
\hline
\end{tabular}

phases include the deployment and installation of network devices $(\sim 25 \%)$, the production of components in network devices $(8-10 \%)$ and other related processes involved $(\sim 5 \%) .{ }^{1}$ For the purpose of this paper, only the network energy consumption due to its usage is studied. Note, however, that the other energy consuming phases of the network life cycle should be considered in further detailed analyses.

Considering the wide variety of devices that take part in the energy consumption of a NGAN, some initial assumptions have been made to limit the number of variables in the analysis.

The scopes for the study are the main active components of the network (not only their usage consumption but also their powering, cooling/air conditioning and other auxiliary requirements) and the end-user facilities (CPEs and ONTs).

It must be noted that the energy consumption of the customers' own house equipment is defrayed by the end users and not by the operator deploying the network, and so, these factors are excluded from the economic balance presented below. This aspect contributes significantly to the overall ICT carbon footprint and should be taken into account in a more detailed analysis. Nevertheless, the wide variety of equipment solutions that can be found in vendor markets make it difficult to study the contribution of this aspect to the energy consumption model, even in the form of a simple percentage (Bolla et al., 2010).

The estimations of power consumption for the different types of technologies have been calculated using the maximum power allowances provided by the standards listed in the regulatory initiatives section. These levels are stated for each technology.

The reference price/KWh set for the cost calculations is $0.14 € / \mathrm{KWh}$.

\subsection{Demographic data}

For the numerical calculations, the model will use a classification in geographical zones with population density as the basic parameter affecting the rolling out of a next-generation broadband access network. The nation of Spain ${ }^{2}$ is used as a case study, and the region was divided into 10 zones $^{3}$ (Table 1 ). The motivation for this division lies in obtaining more precise estimations in the "grey" areas that the competitive market providers could reach in the medium term as a function of technology, demand and public policies. In fact, in Spain, about one quarter of the population lives in the 500-100 inhabitants/ $\mathrm{Km}^{2}$ area, where the population density typical of suburban zones ends and the density typical of rural areas begins. About $46 \%$ of the population lives in urban areas (above 1000 inhabitants $/ \mathrm{Km}^{2}$ ), with an additional $10 \%$ in lower-density suburban areas. Remote rural areas (less than 50 inhabitants $/ \mathrm{Km}^{2}$ ) make up $12 \%$ of the population.

\subsection{Traffic and demand assumptions}

Because the energy consumption of the active components scattered over the network is dependent on the amount of data traffic passing through them, which depends in turn on the users connected to the network at any given time, it is important to define this dependence when describing the energy consumption of the overall network.

\footnotetext{
1 The rates vary depending on the access network of choice.

2 The model described in the paper would be applicable without major modifications to most European countries. However, apart from the direct relevance of the case of Spain as a main European instance for NGAN deployment, note that the data for Spain are relatively similar to the Euroland scenario (Forge et al. 2005). The total population for this area is 46.7 million inhabitants, which is the mean of seven European states: France, Germany, Italy, Holland, Spain, Sweden and the United Kingdom. Demographically, Euroland is made up of a few urban areas with a high population density, a greater number of suburban areas, many rural areas and few remote areas. Last, there are 15.4 million households in Euroland, and 17.3 million of the total inhabitants are employed by 3.2 million companies.

${ }^{3}$ Previous studies usually considered 3-7 zones. For instance, in the Euroland scenario (Forge et al., 2005), it was assumed that $50 \%$ of the population lived in urban areas ( 6000 inhabitants $/ \mathrm{km}^{2}$ population density), $35 \%$ in suburban areas (500 inhabitants $/ \mathrm{km}^{2}$ density) and approximately $15 \%$ in rural areas (30 inhabitants $/ \mathrm{km}^{2}$ density). Gómez-Barroso and Robles-Rovalo (2008) chose to divide Mexico into 7 zones for WiMAX calculations. Seven divisions were also used in Jeanjean (2010) for NGAN calculations. Analysis Mason (2009), apart from London, also selected 7 zones for its study of fibre deployment in the UK, excluding the rural and remote areas.
} 
As stated by Baliga et al. (2001) and Bianco et al. (2007), the choice of a constant behaviour can be taken as a valid approach pending a further and exhaustive traffic model. To explain this approach, it must consider that the active components do not continually operate at a $100 \%$ utilisation cycle. In fact, a behaviour model such as the one suggested by Verizon (2009) could be beneficial. This approximation sets the total power balance of an active element as defined by a percentage of the power consumed in its $100 \%, 50 \%$ and $0 \%$ utilisation cycles, each one rated by a different coefficient.

Energy consumption can be highly dependent on the traffic patterns of the users. Because of this factor, up to a $30 \%$ reduction in power demand can be achieved between the full and stand-by states in network equipment (Verizon, 2009; Bolla et al., 2010).

In this paper, the interfaces are considered to be at their $100 \%$ duty cycle constantly ( $24 \mathrm{~h}$ per day). Thus, the total energy consumed in one year can be calculated by a simple multiplication of the power consumption of each device per hour by a power factor of 8760 ( $24 \mathrm{~h}$ times 365 days a year).

However, the service demand is also an important factor. In an isolated network general energy consumption model, no knowledge of the consumer behaviour should be taken into account, but for a general view of the complete Spanish scenario, it is necessary to make some demand assumptions as in Feijóo and Gómez-Barroso (2010). ${ }^{4}$

The study on the energy consumption during the network usage presented in this paper defines the behaviour of the network once deployed. In this situation, a take-up ratio of $80 \%$ and a $20 \%$ churn ratio ${ }^{5}$ are defined. It would be interesting to study the implications of energy in cost balancing during the network deployment phase, but for this purpose, it would be necessary to present a clear deployment strategy as the energy consumption would be conditioned to the zone selected.

\subsection{Network sizing assumptions}

The energy consumption model would be incomplete if only isolated networks are analysed. For a full general overview of the network behaviour in the Spanish framework selected some other implications must be taken into account.

The network sizing for each access area, obtained from Feijóo and Gómez-Barroso (2010), requires some corrections for a proper extrapolation to the complete density zone.

For this purpose, the data of the average premises (users) per municipality is used as a rate for the measurement of the network deployment performance. The number of maximum premise covered by the access area divided by the average premise per municipality for each zone is used as a correction factor. In the zones where this number is lower than 1 no correction is needed as the full network is exploited, so in those cases the factor taken is $1 .^{6}$

This is explained because many municipalities contain fewer premises than that for which the access area was intended and therefore the rest of the network is not used even fully deployed. The correction factor is used with the intention of alleviating the effect this fault would have in the complete scenario results. This factor affects the energy required by cabinets and OLTs that are not fully used but still computes as power consumption in FTTH-PON and FTTX-VDSL networks. On the other hand in FTTH-PtP networks as the energy is consumed only for each subscriber even if the coverage sizing is higher than the necessary so the correction factor has no effect on this case. In no case customer premises equipment is sensitive to the network correction factor because this equipment is not active unless the premise is subscribed to the user.?

\subsection{Economic repercussions of the energy consumption of the network}

Energy consumption has large repercussions on the costs of network operation. As the cost of energy continually rises, this aspect can represent a strong barrier towards the economic viability of NGAN deployments (Bianco et al., 2007).

Given the wide range of devices for the deployment of these networks, the data related to energy consumption may become a critical point while selecting the appropriate network elements. Thus, energy consumption could become an important criterion for the design of future devices (Bianco et al., 2009).

\subsection{Regulatory initiatives}

Some regulatory initiatives have already begun to delimit and clarify the matter of energy consumption in NGAN equipment. Among these initiatives are the following:

- European Commission: Code of Conduct on Energy Consumption of Broadband Equipment (EC, 2008a).

- ETSI: TS 102 533: EE - Energy consumption in BB Telecom Network Equipment (ETSI, 2008).

- Verizon: Verizon NEBS Compliance: Energy Efficiency Requirements for Telecommunications Equipment (Verizon, 2009).

${ }^{4}$ One potential choice would be to decide that the network is universal and subject to minimum demand assumptions; this approach is employed by De Antonio et al. (2006). However, others consider this approach to be unrealistic.

${ }^{5}$ The churn rate will be used in a subsequent analysis on the network behaviour across time according to changes in demand.

6 This way no further implications in the overall results would be derived.

7 Some resistance power consumption must be assumed only by simply connecting the equipment to the network, but it is assumed to be so low as to not be taken into consideration for this papers purpose. In a deeper analysis this factor must be sure taken into account not only for CPE devices but for any other equipment connected as for the OLT in FTTH-PIP. 
With these guidelines, some of the figures on the energy requirements for the operation of broadband equipment are fixed and are thus used in different stages of the energy model depicted below.

\section{Model description: architecture and energy consumption}

\subsection{Fibre-To-The-Home (FTTH)}

There are different FTTH network architectures, depending on whether a single fibre is used for a subscriber in a Pointto-Point configuration (PtP) or some portion of the fibre is shared among customers (point-to-multipoint); here presented as a Passive Optical Network (PON). Both possibilities are detailed and analysed below.

The PtP simple architecture is based on the deployment of fibre from the exchange to the customer premises, as depicted in Fig. 1. In this case, no passive elements are placed between the local exchange and the customer premises, meaning that less power is required to send the signal through the fibre (Keymile, 2008).

In this configuration, it is only necessary to operate the laser diodes that deliver information to the users subscribed to the network service. Customers without service do not need to be connected to an optical port, so the number of premises connected equals the number of premises subscribed. The number of local exchange offices (and therefore of OLT) will depend directly on the number of connected users, the network penetration and the percentage of subscribed users. For this reason, the cost per user is constant and the energy consumption is directly related to the number of users.

An extra factor must be added to the OLT power consumption because of the cooling requirements of the equipment. This factor adds an extra $60 \%\left(\alpha_{\text {cooling }}\right)$ of the energy consumption made by the OLT to the total energy consumption on the Local Exchange (Cucchietti, 2009; Bolla et al., 2010; Keymile, 2011).

$$
P_{\text {cooling }}=P_{\text {Opt DSLM }} \times 0,6
$$

The end-user equipment (ONT) cooling factor approaches zero because in this stage, the cooling process occurs in a passive way and therefore does not consume energy (Pande, 2010). ${ }^{8}$

It is necessary to provide some details before defining a function of the energy performance of the network.

- OLT power consumption: $5 \mathrm{~W} / \mathrm{user}$ (EC, 2008b).

- ONT (CPE) power consumption: 3 W/user (Keymile, 2011).

- The number of subscribed users depends on the network deployment rate at any given time. The maximum threshold is 75\%. This rate can change depending on the market share of the network operator, but for the purpose of this paper, a reference peak value of an incumbent operator is used.

On the basis of these data, the total energy balance of an access area is determined by the next two equations:

$$
\begin{aligned}
& E_{\mathrm{OLT}}(W)=\left(P_{\mathrm{OLT}}+P_{\text {cooling }}\right)=P_{\mathrm{OLT}} \times\left(1+\alpha_{\text {cooling }}\right)=P_{\mathrm{OLT}}(1+0,6) \\
& E_{\text {Total }}=E_{\mathrm{OLT}}+E_{\mathrm{ONT}}
\end{aligned}
$$

Fig. 2 indicates the typical architecture of a FTTH-PON network. After the local exchange, several levels of passive optical splitters distribute the signal before it reaches the optical network terminal (ONT) placed in the customer premises. In this paper, just one level of splitting is used. The splitting process translates into an increase in the power required to send the signal down from the OLT and up from the ONT. This need is caused by a loss of dB level of the signal that goes through the splitter in both directions. This insertion loss depends on the splitting factor ( $n$ ), which is $17 \mathrm{~dB}$ for a 32 -fold splitter. ${ }^{9}$

The focus of the energy consumption analysis of these types of networks is therefore placed in the OLT and ONT stages, just as in the former PtP but with one technicality that must be taken into account.

The key difference between these two access network solutions (which is also observed in FTTx/VDSL deployments)is that the homes passed are now considered to be subscribed homes, and the slot in the OLT is designed to the premise even if no service is provided (Keymile, 2008, 2011). Therefore, depending on the number of subscribed users ${ }^{10}$ (penetration rate), the service requires the number of interfaces related to the bandwidth allocated to each network subscriber (in this case, $50 \mathrm{Mbps}$ per user). This requirement translates into network resizing if an increase in bandwidth per user is necessary.

All of the numbers about the potential user distribution and the fibres used that were considered for the calculations are summarised in Table 2.

The total energy consumption in the access network area controlled by one OLT equipment is calculated by considering all of the downlink interfaces and the corresponding uplink interfaces that are needed, where the total number of these two kind of interfaces depend, as stated before, on the total bandwidth provided to the users (EC, 2008b).

\footnotetext{
${ }^{8}$ This approach is used from now on for every access network technology analysed in the paper.

${ }^{9}$ The power required for each splitter is $22 \mathrm{~W}$, independently from the splitting factor (Keymile, 2011).

${ }^{10}$ Note that the number of users $(n)$ served by a single fibre depends basically on the density zone, the level of quality (bandwidth per user) and the requisites derived from possible re-use of existing infrastructures.
} 


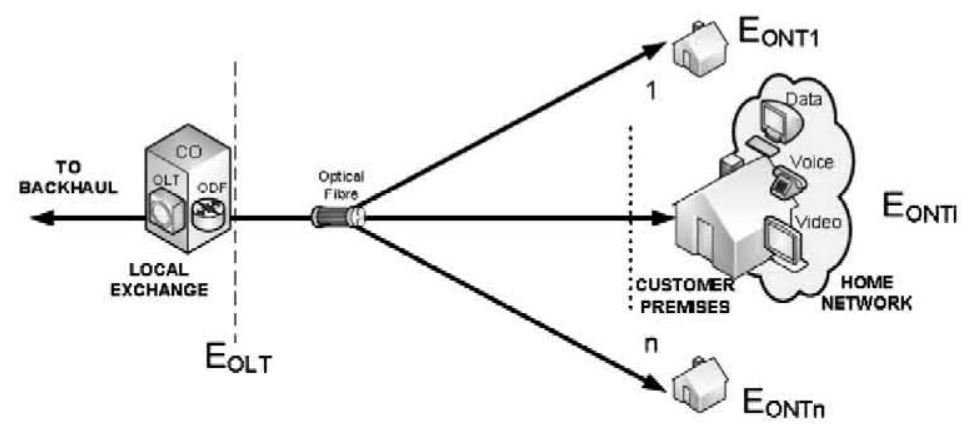

Fig. 1. FTTH-PtP access area architecture.

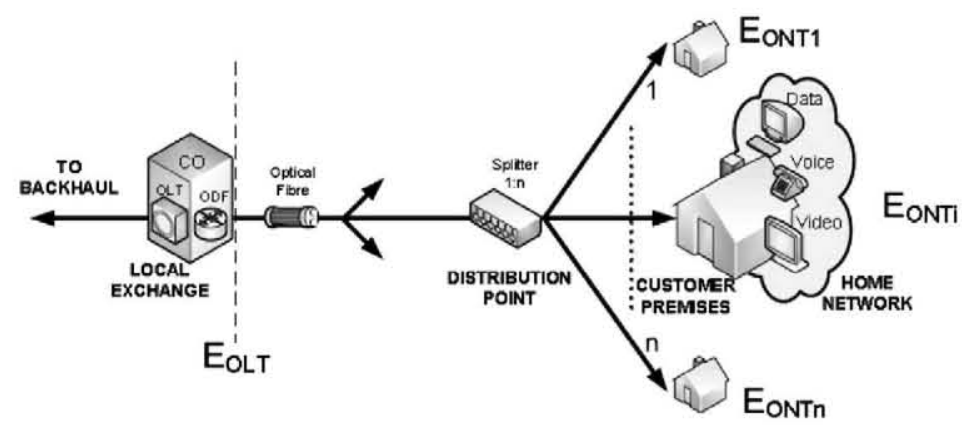

Fig. 2. FTTH-PON access area architecture.

Table 2

Number of potential users (premises) per access area, splitter ratio and number of fibres, division point, cabinets and distribution boxes per type of zone (Feijôo and Gómez-Barroso 2010).

\begin{tabular}{|c|c|c|c|c|c|c|c|c|c|c|}
\hline Zone & 1 & Il & Ill & IV & V & VI & VII & VIII & IX & $\mathrm{X}$ \\
\hline $\begin{array}{l}\text { Number of households and } \\
\text { businesses }\left(n_{\text {user }}\right)^{\text {a }}\end{array}$ & 963.482 & 2.090 .404 & 1.185 .622 & 2.575 .576 & 1.446 .293 & 3.190 .138 & 1.061 .590 & 1.453 .938 & 258.753 & 134.524 \\
\hline $\begin{array}{l}\text { Number of users per access } \\
\quad \text { area }\left(n_{\text {area }}\right)\end{array}$ & 16,384 & 16,384 & 16,384 & 16,384 & 16,384 & 16,384 & 4096 & 2048 & 512 & 256 \\
\hline $\begin{array}{l}\text { Number of areas required } \\
\text { to cover the density } \\
\text { zone }\end{array}$ & 59 & 128 & 72 & 157 & 88 & 195 & 259 & 710 & 505 & 525 \\
\hline $\begin{array}{l}\text { Minimum number of fibres } \\
\left.\text { at the exchange ( } n_{\text {fibre }}\right)\end{array}$ & 256 & 256 & 256 & 256 & 256 & 256 & 64 & 32 & 8 & 8 \\
\hline Number of splitters & 32 & 32 & 32 & 32 & 32 & 32 & 16 & 16 & 4 & 4 \\
\hline Number of cabinets $\left(n_{\text {cab }}\right)$ & 32 & 32 & 32 & 32 & 32 & 32 & 16 & 16 & 4 & 4 \\
\hline $\begin{array}{l}\text { Number of user served per } \\
\text { cabinet }\end{array}$ & 512 & 512 & 512 & 512 & 512 & 512 & 256 & 128 & 128 & 64 \\
\hline
\end{tabular}

${ }^{\text {a }}$ Taken into account the $80 \%$ demand assumption stated before.

The calculations can be made using the next equation:

$$
E_{\text {OLT }}=E_{\text {Uplink }}+E_{\text {Downlink }}+E_{\text {cooling }}=\left(n_{\text {up }} \times p_{\text {uplink }}+n_{\text {down }} \times p_{\text {downlink }}\right) \times\left(1+\alpha_{\text {cooling }}\right)
$$

where $E_{\text {OLT }}$ is the total energy consumed in the number of links required to cover an access area, $n_{\text {up }}$ and $n_{\text {down }}$ are the number of up and down links necessary for the specific bandwidth requirements and $p_{\text {uplink }}(15 \mathrm{~W})$ and $p_{\text {downlink }}(18 \mathrm{~W})^{11}$ are the power consumption of each up and down links, respectively.

Because of loss in the splitters, a higher power consumption rate of $10 \mathrm{~W}$ for the CPE is assumed (Keymile, 2011).

\subsection{FTTX/VDSL}

FTTx is a generic term for those technologies that bring fibre from the central office closer to the subscriber and where the final distribution towards users is made via an alternative means, such as copper wire. The different varieties arise from the

\footnotetext{
11 These are 2010 Tier Levels EC, 2008.
} 


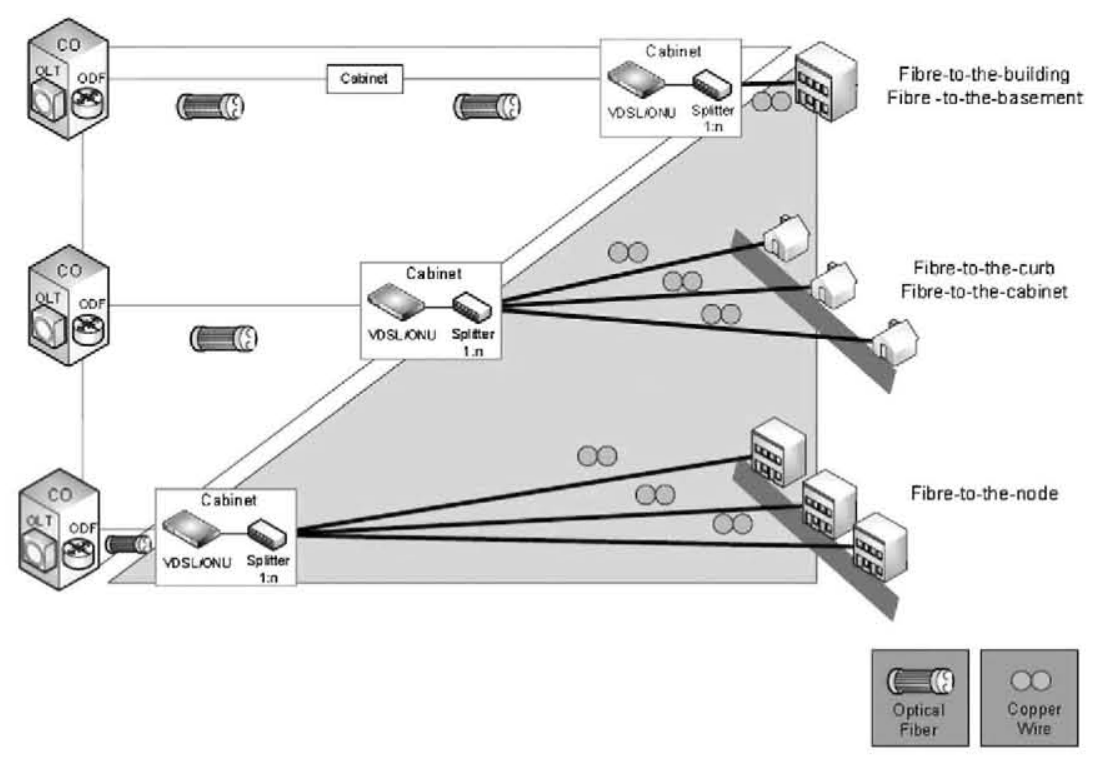

Fig. 3. A comparative view of FTTB, FTTC and FTTN.

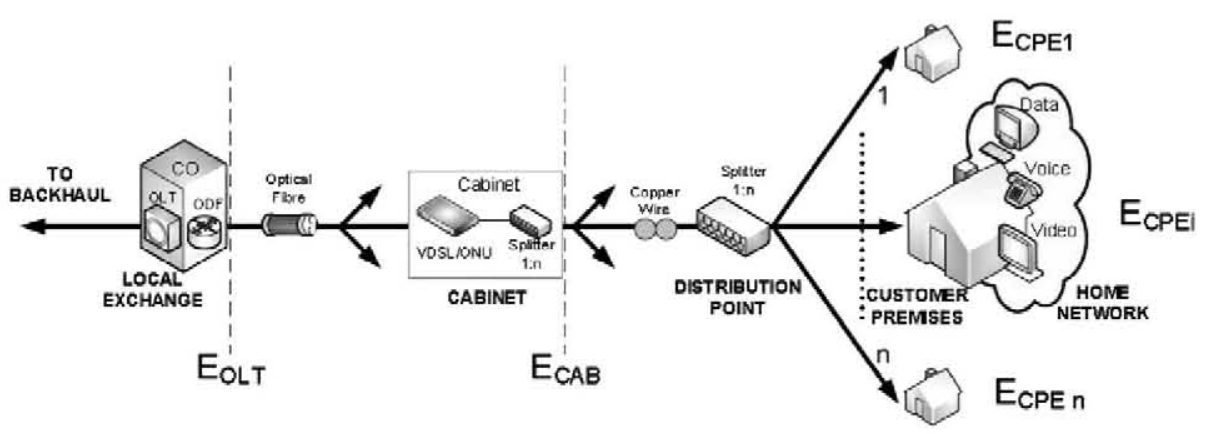

Fig. 4. FTTx/VDSL access area architecture.

location of the termination point of the optical part of the network: FTTB (Fibre to the building/basement), FTTC (Fibre to the curb/cabinet) or even FTTN (Fibre to the node). Fig. 3 shows the different options for FTTx deployments.

The VDSL/xDSL technologies can be considered equivalent to these FTTx solutions from the network perspective, as they provide access on copper wire and approach the user as much as possible, using fibre to increase the bandwidth.

Fig. 4 depicts the basic architecture of FTTx/VDSL networks, taking into account the points of the network at which energy consumption takes place. From the local exchange, the active devices are the OLT, the VDSL/ONU (Optical Network Unit), the DSLAM (Digital Subscriber Line Access Multiplexer), and the Customer Premises Equipment (CPE).

The OLT and CPE power consumption is calculated similarly to the FTTH-PON, using the same reference levels previously outlined.

For the DSLAM, if we assume an access bandwidth of $50 \mathrm{Mbps}$ (downstream), the total uplink capacity of the cabinet needs to be $25,6 \mathrm{Gpbs}$, thus requiring 3 up-links of $10 \mathrm{Gbps}$ each to provide access to the cabinet. The power consumption per cabinet is set at $1334 \mathrm{~W}$ (including the cooling requirements), and this behaviour is constant ${ }^{12}$ (ETSI, 2008a,b; Lastres et al., 2010).

The total power demand of FTTx/VDSL networks can be calculated by adding the power demanded by the OLT, DSLAMs and the total power derived from the use of CPEs from end users.

$$
E_{\mathrm{TOTAL}}=E_{\mathrm{OLT}}+E_{\mathrm{CPE}}+E_{\mathrm{CABINET}}
$$

\footnotetext{
${ }^{12}$ As stated in the traffic assumptions, the normal behaviour of active elements is not constant and a traffic modelling must be performed. Pending this improvement, a constant rate is enough for the approximation of these results.
} 


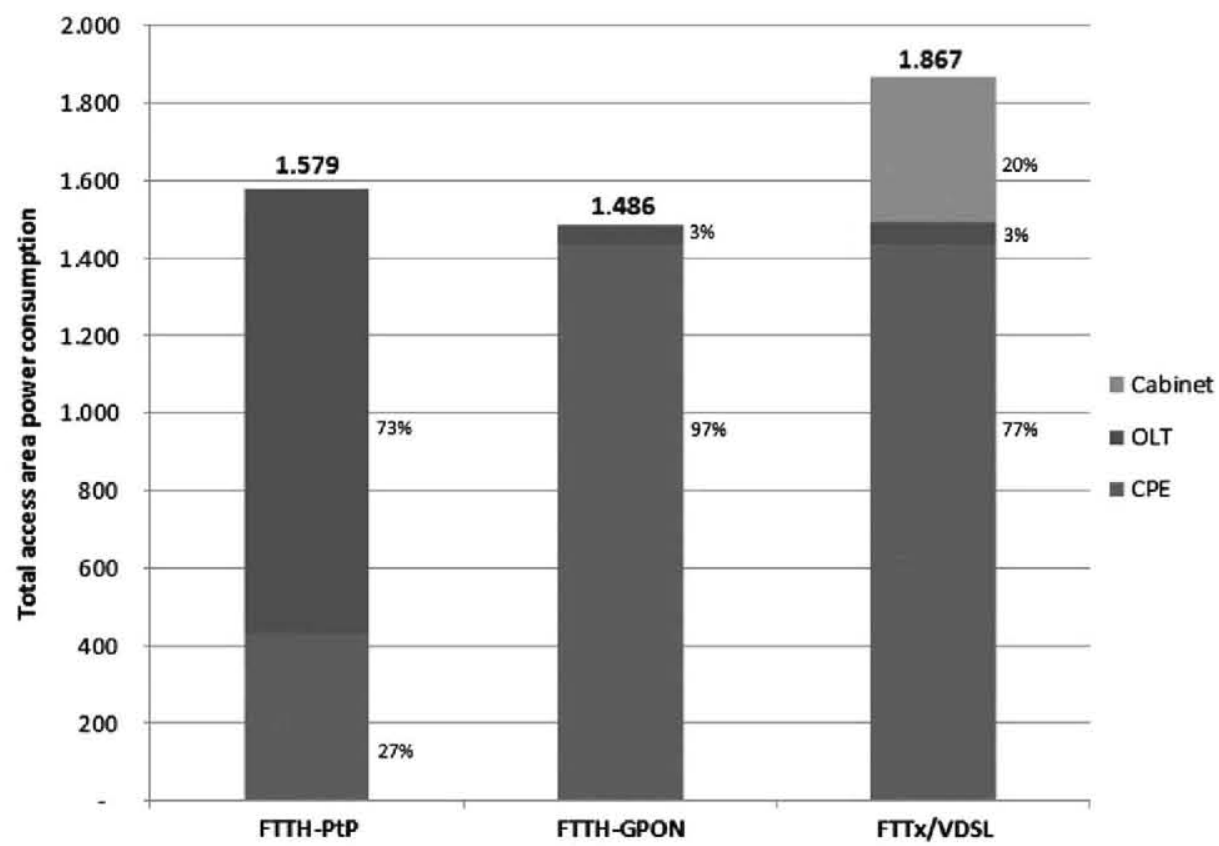

Fig. 5. Percentage of power consumption for each active element of the fibre-based networks vs. the total power consumption in the access area (according to the sizing for density zone VI).

\section{Results discussion}

The main aim of this energy model for NGANs is to provide power consumption results for fibre-based access networks in a set of geographic distribution typical of EU countries. There are two main results deriving from the application of the model: to determine which deployments will result into more energy efficient solutions and to obtain estimations of the economic costs due to the power consumption.

In the following the next topics are discussed: the analysis of the relative importance of each energy consumer element in the access network, the average premise cost for access areas according to the specific network sizing used, the study of the factors affecting the total energy and cost calculations for the complete demographic framework and the study of the power consumption in the different density zones for FTTx/VDSL. ${ }^{13}$

The analysis of the relative importance of each device in the networks' total energy consumption is capital for the selection of design strategies for those elements, aimed at improving their power consumption efficiency.

In FTTP-PtP networks, the share of the active element power consumption is constant throughout the ten zones. This characteristic is due to the previously explained fact that the network consumption is defined by the premises subscribed and not by the homes passed. There is a linear dependency of the energy on the number of users. Within the data framework, the percentage of the power consumption made by the CPE is $27 \%$ and that made by the OLT is $73 \%$. The higher contribution of the OLT towards the power consumption share is due to the need of using one interface for each costumer, in contrast to PON and FTTx/VDSL networks where the optical signal is shared by several customers.

However, in FTTH-PON and FTTx/VDSL networks, the non-linear dependency of the energy on the number of users connected to the local exchange translates into a variation of the power share of the active elements. These variations are more remarkable in the less dense areas because of the sizing required within these specific zones. The number of users and their geographic distribution affects the level of "occupancy" of both OLTs and cabinets. The higher output required by the laser diodes in FTTH-PON and FTTx/VDSL (due to the splitting factor formerly explained) is a critical fact that makes the difference. This does weaken the advantage of PON over PtP networks, but on the whole power consumed by the formers is lower than by the latters. To date, manufacturers have not placed significant emphasis on the efficiency of laser diodes, but it could change with the development of green IT (Keymile, 2011).In fact, the level of power consumption for FTTx/VDSL access areas is just slightly higher compared to the levels of FTTH-PtP model, even with the contribution of the power due to the cabinets. This means in short that if lower power consumption levels for the CPEs used in FTTH-PON and FTTx/VDSL deployments were achieved, it will translate into a significant reduction on the energy consumption compared to that of FTTH-PtP networks.

\footnotetext{
${ }^{13}$ This technology has been selected as the design of the network implies more devices so the power and cost results present a more complex behaviour.
} 


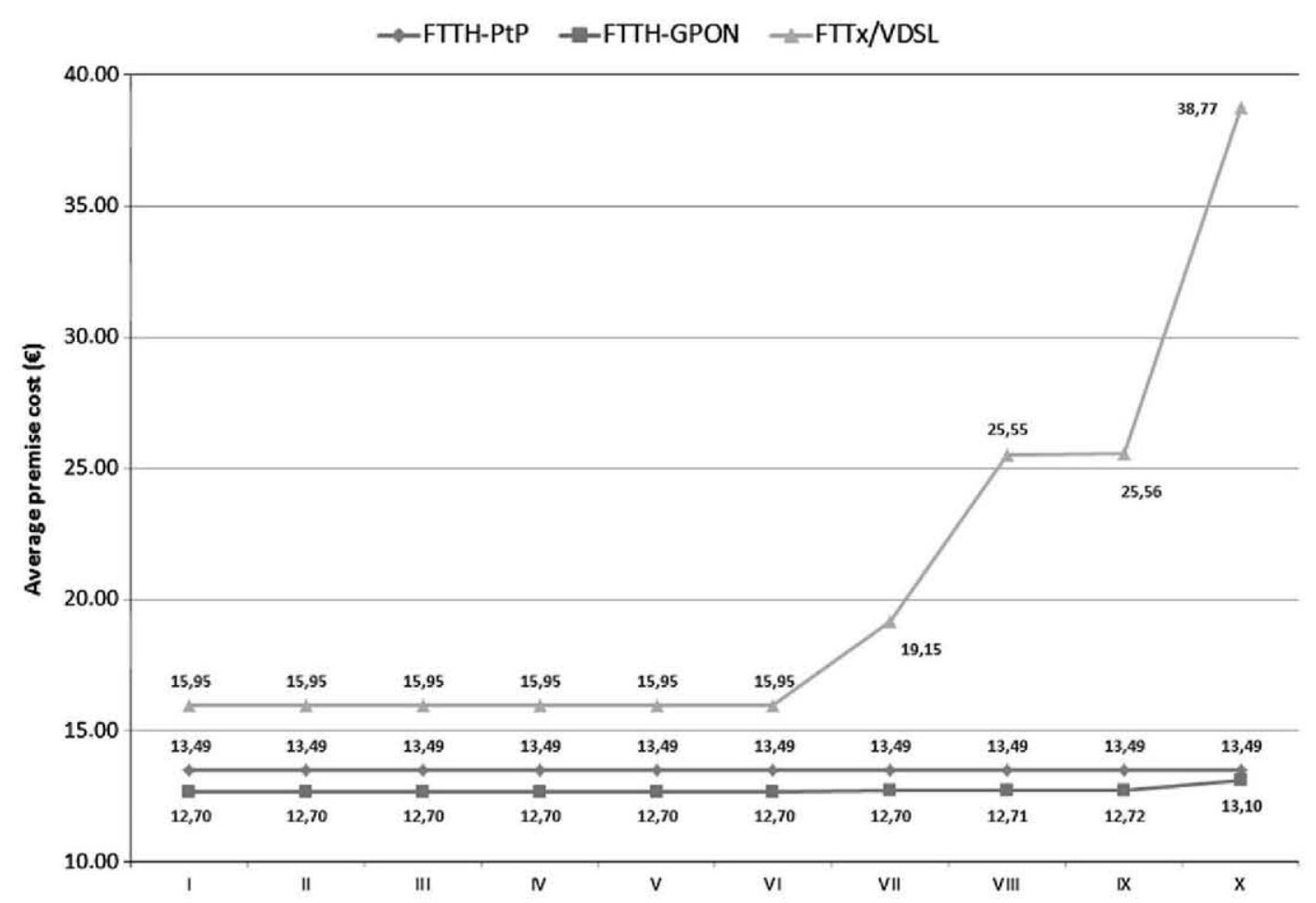

Fig. 6. Average premise energy cost $(€)$ in each access network.
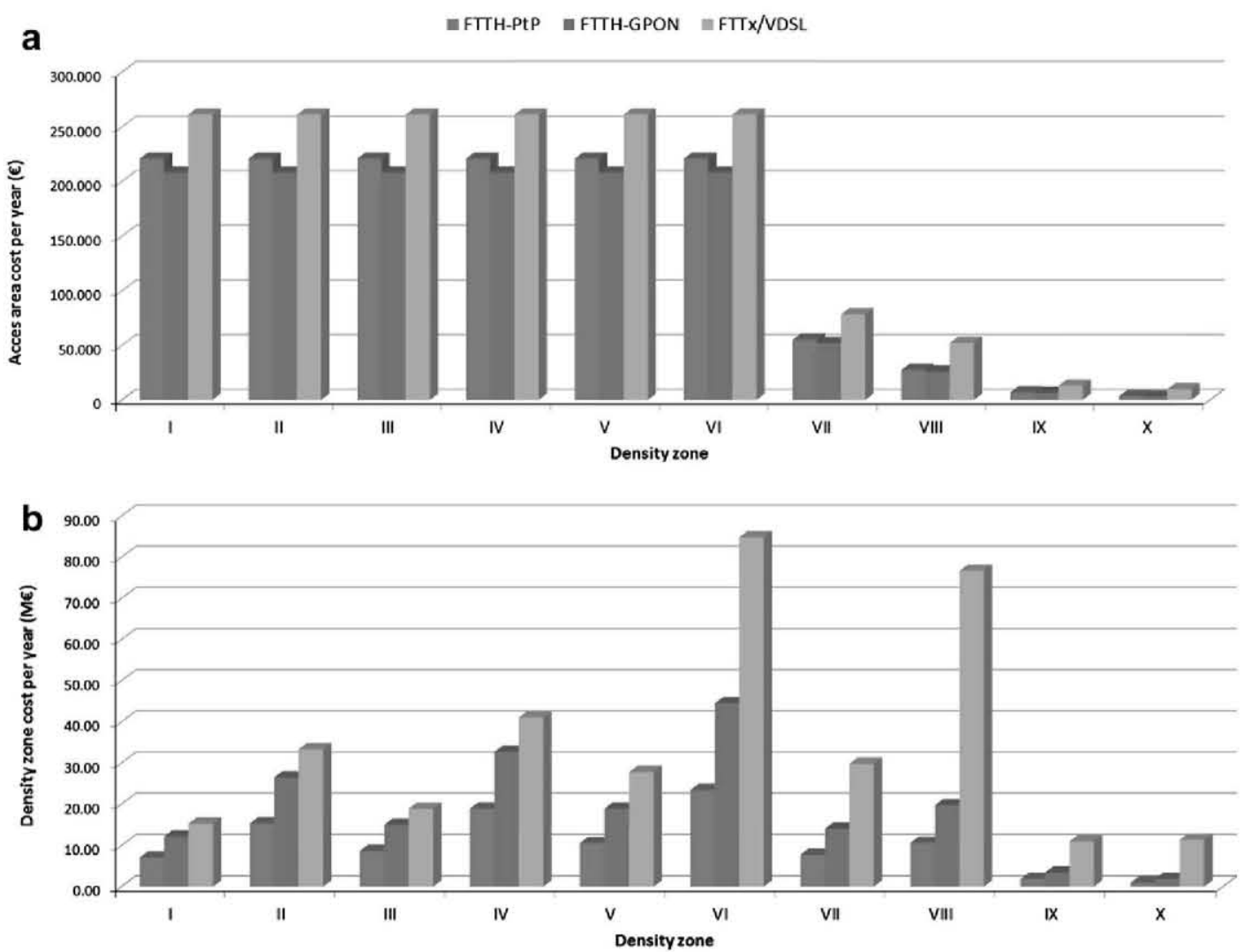

Fig. 7. (a) Access area cost per year (c); (b) Total cost of each density zone per year (MC). 


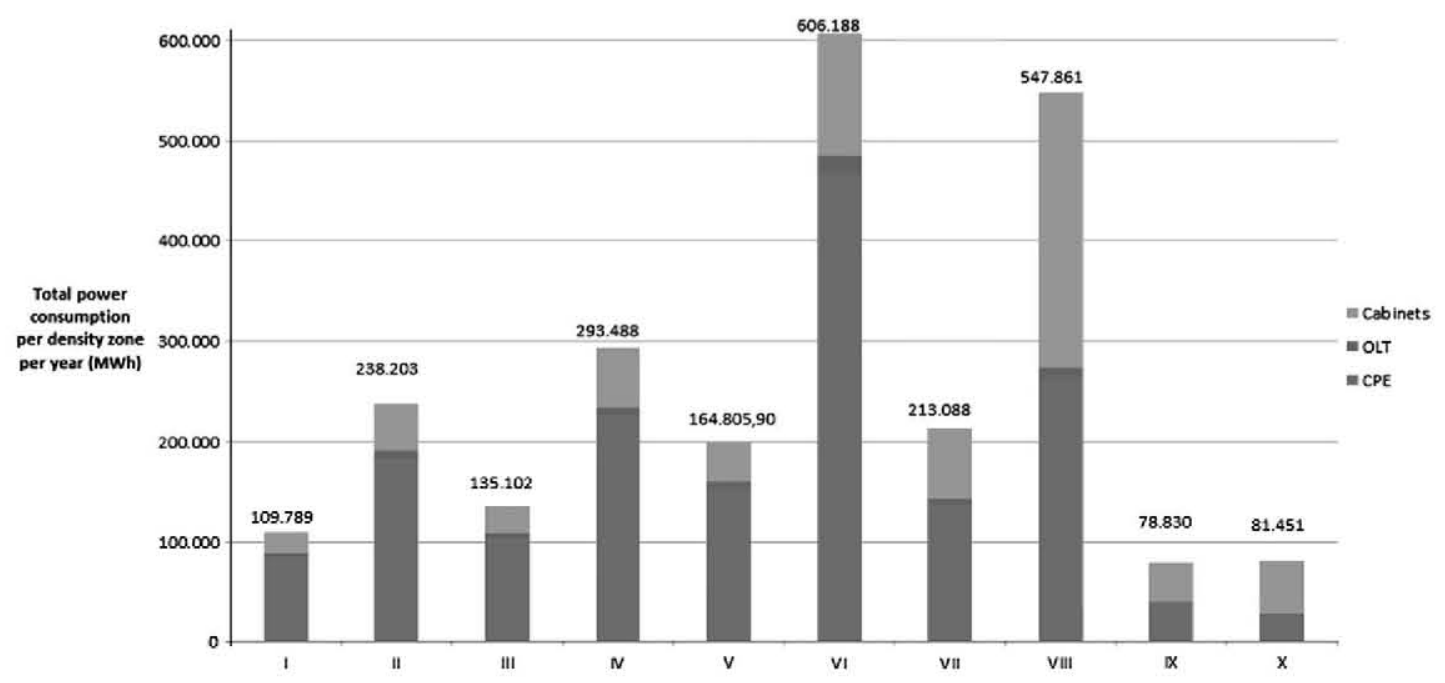

Fig. 8. Total power consumption per density zone (MWh) of the FTTx/VDSL architecture and participation of each network active element.

Table 3

Results summary.

\begin{tabular}{lll}
\hline Technology & FTTH-PtP & FTTH-PON \\
\hline Total energy consumption for the Spanish territory $(\mathrm{MWh})$ & 754.832 & 1.352 .301 \\
Total cost per year for the entire Spanish territory $(\mathrm{M} €)$ & 105,68 & 189,32 \\
\hline
\end{tabular}

Fig. 5 shows the total power consumption of each access are for the data used in density zone VI (500-100 inhabitants/ $\mathrm{Km}^{2}$, selected for its potential relevance ${ }^{14}$ ) and the percentage of power consumption of the different active elements that compose each access network.

Regarding the average premise energy cost for each access area (Fig. 6), some ideas are hereby exposed. For PtP networks this figure is constant and independent of the area, because each resource is allocated to the customer only when the premise is connected to the network. In low density areas, as the sizing of the network requires the use of a higher percentage of OLTs (and cabinets in the case of FTTx/VDSL) in relation to the number of users, the importance of these elements in the power consumption share of each access areas increases. This is more evident for access areas from VII to X where the decrease in the number of users covered for each density zone is not followed in the same ratio by the decrease in the number of cabinets used. The implication in the average premise cost of the OLTs and cabinets is therefore more remarkable and as thus an increase is shown in the less dense regions.

For the subject of the factors affecting the total energy consumption and the total cost for each complete density zone depicted some ideas are now here exposed. There are some factors involved in the final shape of cost evolution between access areas and density zones (Fig. 7). These factors are: the access area average cost per premise, the sizing of the network selected, the premises involved in each density zone, the number of areas required to cover each density zone and the network correction factor. For the access areas only the two first factors affected the power and cost calculations. For the density zones the three other factors are used and as the access area data is used as reference for the calculations the first two factors affect indirectly as well.

Finally the power consumption of the FTTx/VDSL networks is now analysed (Fig. 8). In this technology the implication of the correction factor applied is well noted as it affects both the OLT and cabinet consumption. This is particularly important in zones VII to X where cabinets power consumption share is higher and thus affects significantly the total result.

In density zone VII, the number of areas required to cover each density zone reaches a peak. This could be interpreted as if a higher number of users per area should have been assumed, but otherwise the correction factor is the second higher and that means that even for the user coverage selected the average premises per municipality are not enough for an efficient usage of the resources allocated.

To conclude this section, the following Table 3 summarises the results obtained for the whole territory of Spain, given all the data and assumptions explained in the previous sections.

\footnotetext{
${ }^{14}$ It represents more than $24 \%$ of the potential users in Spain, with more than 11 million people (more than any other density zone).
} 


\section{Conclusions}

In this paper, the subject of the energy requirements of the next generation access network has been addressed. This issue is a major concern because this part of the network according to Bolla et al. (2010) is responsible for approximately $70 \%$ of the network energy consumption (the other $30 \%$ is for the transport and core layer). In contrast, the consumption per device in Watt/h (Wh) in the access is the lowest of the three layers (approximately $1200 \mathrm{Wh}$ ), compared with $6000 \mathrm{Wh}$ for the transport layer and $10,000 \mathrm{Wh}$ for the core layer. This imbalance is due to the fact that $94 \%$ of the total devices of the NGN deployment are placed in the access section of the network, whereas the residuary $6 \%$ are spread across the transport and core layer (Bolla et al., 2010).

Looking specifically at the access part of the network, the simplified energy model presented here allows one to draw some general conclusions. It frames some of the architecture network models for fibre-based NGANs and some numbers on a specific user distribution framework that could be used as an energy foundation model, going beyond mere cost deployment patterns. However the common framework shared with these deployment models allows some comparison between the deployment costs and the usage derived, and further demand analysis can be performed concurrently. This all together will help in the decision about the optimal access network deployment.

Some specific conclusions derived from the result discussion section are now presented.

As stated in the results section, the distribution of energy consumption among the active elements of the access network is rather dependent on the technology used. Therefore standardisation bodies should consider the analysis in detail to detect the telecommunication equipment liable for further and deeper research. This type of analysis would encourage vendors and equipment manufacturers to promote the development of more energy efficient devices.

The second of the main conclusions of this study is that energy consumption mainly depends on the architecture and on the sizing of the access coverage area, but is also affected by other access network energy particularities. On the one hand in PtP networks, the fact that premise is only connected to the network when subscribed makes it easier to dynamically resize the network. On the other, OLTs used in PON and VDSL access networks consume less energy (level that depends on the splitting factor and consequently on the bandwidth guaranteed to each premise)because the optical signal is shared by several customers. Defining these and other special features helps identifying the advantages and drawbacks of each technology access network design.

Third, the study of multiple density zones in the Spanish framework that was chosen helps to determine the implications of the sizing required in specific scenarios. Because of this factor, an awareness of the energy implications of the network usage is vital, as the power consumptions are reflected in the future operational costs of the network. The premises are more scattered in low density zones, making the sizing of the network more critical and the extra elements required per user more impactful on both energy consumption and costs.

Fourth, the deployment of each access networks along the demographic framework, especially in the less dense areas, entails some implications. The conclusions derived from the analysis of the single access area energy and cost analysis cannot be extrapolated to the general deployment in the corresponding density zone. The many factors that affect the deployment in each density zone of the technologies examined derive finally in a change of behaviour from the single access area to the general scenario. All in all the energy consumption behaves the same way as investment costs when the areas are aggregated for the overall density zone deployment.

Regarding this last issue addressed, some conclusions can be extracted from the deployment in the Spanish framework selected. PtP access networks are assumed to be the more expensive to deploy due to the high level of resources involved, but the specific requirements implies lower overall energy consumption than that of PON. In low density areas, VDSL networks are entitled to have an advantage in economic terms due to the possibility of reusing the existing copper network. Nevertheless the data obtained show higher energy consumption because of the equipment required (especially in density zone VIII). This has to be taken into consideration in the long term for network deployments as the impact on operational cost would be significant, and should be taken seriously in the deployment strategies specially in the low density areas.

Nevertheless, we have to bear in mind that the results here depicted were obtained in the ideal conditions exposed. Taking into account this, there is certainly room for improvements that could lead to finer approximations. Nonetheless, the simple model depicted and the behaviours and conclusions here exposed would remain valid for improved models.

Finally, note that every effort made by the standardisation bodies, equipment vendors, telecomm operators and public bodies, to set the required energy consumption levels for future equipment and therefore the path for more energy efficient networks, is essential. As the decreasing cost of equipment is counterbalanced by the increasing cost of the energy, an awareness of the importance of a responsible and weighed use of the energy resources in Next Generation telecomm networks is not only a political issue but also a social and economic concern, for the deterrent it would offered for general progress of Information Society.

\section{Disclaimer}

The research within this paper had been developed is funded by the STAREBEI-Programme of the European Investment Bank (EIB) and prepared by independent experts under EIB's supervision. This paper does not in any way represent EIB's official position in regard to the matters here exposed. 


\section{References}

Aguado, A., 2009. Innovación tecnológica y espectro. Regulatory and Economic Policy in Telecommunications 2 (3), 41-48.

Analysys Mason, 2008. The costs of deploying fibre-based next-generation broadband infrastructure. Available from <http://www.broadbanduk.org/ component/option,com_docman/task,doc_view/gid,1036/Itemid,63>.

Analysys Mason, 2009. Competitive models in GPON. Available from <http://www.ofcom.org.uk/research/technology/research/emer tech/sbt/ Analysys Mason GPON_Final_R1.pdf>.

Baliga, J., Ayre, R.W.A., Hinton, K., Tucker, R., 2001. Green cloud computing: balancing energy in processing, storage, and transport. Proceedings of the IEEE 99 (1), 149-167.

Bianco, C., Cucchietti, F., Griffa, G. 2007. Energy consumption trends in the next generation access network - a telco perspective. In: Telecommunications Energy Conference, 29th International (INTELEC 2007) IEEE, Rome, IEEE, pp. 737-742.

Bianco, C., Cucchietti, F., Griffa, G., et al. 2009. Analysis of existing standards on broadband equipment's energy efficiency and proposal of an alternative evaluation methodology. In: Telecommunications Energy Conference, INTELEC 2009, 31st International.

Bolla, R., Bruschi, R., Davoli, F., et al. 2011. Energy efficiency in the future internet: a survey of existing approaches and trends in energy-aware fixed network infrastructures. IEEE Communications Surveys \& Tutorial 13 (2), 223-244.

Bomhof, F., Hoorik, P., Donkers, M., 2009. Systematic analysis of rebound effects for greening by ICT" initiatives. Communications \& Strategies 76 (4th quarter), 77-96.

CMT, 2009. Informe final sobre los resultados del modelo de despliegue de redes FTTH/GPON en España. Available from <http://www.cmt.es/es/ documentacion_de_referencia/redes nueva generacion/anexos/Informe_final_HE_1_2008_09_MDF.pdf>.

Cucchietti, F., 2009. Energy Efficiency in TLC Networks: the Operator and the User perspective, Associazione Gruppo Telecomunicazioni e Tecnologie dell'Informazione - GTTl. Available from <http://www.gtti.it/GTTI09/files/presentations/GREEN/Cucchietti.pdf>.

De-Antonio, J., Feijóo, C., Gómez-Barroso, J., et al. 2006. A European perspective on the deployment of next generation networks. The Journal of the Communications Network 5 (2), 47-55.

EC, 2008a. Code of Conduct on Energy Consumption of Broadband Equipment. Version 3.

EC, 2008b. Communication on addressing the challenge of energy efficiency through information and communication technologies. Available from <http:/ ec.europa.eu/information_society/activities/sustainable_growth/docs/com_2008_241_1_en.pdf>.

Effenberger, F., El-Bawab, T.S., 2009. Passive optical networks (PONs): past, present, and future. Optical Switching and Networking 6 (3), $143-150$.

ETSI, 2008a. ETSI TS 102533 - Environmental Engineering (EE): Measurement methods and limits for Energy consumption in Broadband Telecommunication Networks Equipment.

ETSI, 2008b. TS 102 533, Environmental Engineering (EE) Measurement Methods and limits for Energy Consumption in Broadband Telecommunication Networks Equipment, v1.1.1. Available from <http://www.etsi.org/deliver/etsi_ts/102500_102599/102533/01.01.01_60/ts_102533v010101p.pdf>.

Feijóo, C., Gómez-Barroso, J. L., 2010. A prospective analysis of the deployment of next generation access networks: looking for the limits of market action. The case of Spain, NEREC Workshop, Madrid, 29-30 November, 2010.

Forge, S., Blackman, C., Bohlin, E., 2005. The demand for future mobile communications markets and services in Europe. Available from <http://ftp.jrc.es/ eur21673en.pdI>.

GeSI, 2008. SMART 2020: Enabling the low carbon economy in the information age. Available from <http://www.gesi.org/LinkClick.aspx?fileticket= tbp5WRTHUoY\%3d\&tabid=130>.

Gómez-Barroso, J.-L., Feijóo, C. 2009. Policy tools for public involvement in the deployment of next generation communications. Info 11(6), 3-13.

Gómez-Barroso, J.L., Feijóo, C., 2010. A conceptual framework for public-private interplay in the telecommunications sector. Telecommunications Policy 34 (9), 487-495.

Gómez-Barroso, J., Robles-Rovalo, A., 2008. Wireless hopes for universal service in developing countries: an assessment of the Mexican context. Info 10 (56), 83-91.

Griffa, G., Radice, l., Bianco, C. 2010. Carbon footprint of next generation fixed networks. In: Telecommunications Energy Conference (INTELEC), 32nd International, Orlando, FL, USA, IEEE, pp. 1-6.

IEA, 2010. Energy Technology Perspectives. Executive Summary.

ITU, 2008. NGNs and energy efficiency. Available from <http://www.itu.int/dms_pub/itu-t/oth/23/01/T23010000070002PDFE.pdf>.

Jeanjean, F., 2010. Financing the next generation infrastructures. Consumer subsidies or infrastructure subsidies?. FuroCPR 2010. Brussels.

Keymile, 2008. Ethernet point-to-point vs. PON - a comparison of two optical access network technologies and the different impact on operations. Available from <http://www.keymile.com/media/de/internet/about_keymile/media_centre/white_paper/White_Paper_EPtP_vs_PON.pdf>.

Keymile, 2011. FTTH/FTTB: point to point vs. PON", 18.03.2011. Available from <http://unistelekom.ba/images/ftth-fttb\%20ptp\%20vs\%20pon.pptx>.

Labouze, E., Des Abbayes, C., Iyama, S., et al., 2008. Impacts of information and communication technologies on energy efficiency. Final report. Available from ftp://ftp.cordis.europa.eu/pub/fp 7/ict/docs/sustainable-growth/ict4ee-final-report_en.pdf.

Lastres, C., Feijóo, C., Martín, Â., et al. 2010. An Energy Consumption Model for Next Generation Access Networks". 3rd CMI Conference - "Green ICT - is ICT part of the solution or the problem? Aalborg University Copenhagen.

Nerandzic, D. 2008. Emerging technologies and their implications on regulatory policy. In: 17th Biennial Conference of the International Telecommunications Society "The Changing Role of the Telecommunications Industry and the New Role for Regulation", Montreal, Canada.

Ouvrier, S. 2008. Driving key technologies for next generation mobile networks. ICT Mobile Summit 2008. IIMC International Information Management Corporation Ltd., Stockholm, Sweden.

Pande, A., 2010. Green Effect of FTTH/FTTB Networks, FFTH Council APAC, March 25, 2010. Available from <http://www.cmai.asia/events/pdf/CMAIFTTH(CAPGreeneffect\%20AnilPande).pdf>.

Sutherland, E. 2009. Climate change: the contribution of telecommunications. Communications \& Strategies 76(4th quarter), 61-76.

Teppayayon, O., Bohlin, E., Forge, S. 2009. Will broadband networks make the world greener? Evaluating pros and cons of broadband development. Communications and Strategies 76(4th quarter), 19-38.

Verizon, 2009. Verizon NEBS Compliance: Energy Efficiency Requirements for Telecommunications Equipment, Verizon Technical Purchasing Requirements, VZ.TPR.9205. Available from <http://www.verizonnebs.com/TPRs/VZ-TPR-9205.pdf> 